\title{
BORRANDO LAS DIFERENCIAS ENTRE EL CAMPO Y LA CIUDAD

\author{
REVISTANDO EL LEGADO DE KIBUTZ ISRAELI
}

EhUd MANOR

Doctor en Historia. Profesor Ariel University, Israel

https://dx.doi.org/10.12795/astragalo.2016.i21.06

\section{INTRODUCCIÓN}

Siendo tanto historiador como hijo y miembro de un kibutz en Israel, en este ensayo mi intención es proponer una mirada histórica del kibutz, viéndolo como un elemento del amplio contexto utópico del modernismo.

En el primer apartado explicare sintéticamente el ideario básico del kibutz, viéndolo desde dos perspectivas esenciales: el marxismo y el nacionalismo. No es menos esencial aclarar que en contradicción total con la idea convencional desarrollada más que todo en la época de la Guerra Fría, socialismo y nacionalismo no necesariamente se excluyen uno al otro sino que se pueden complementarse, siempre y cuando se respeten los básicos derechos humanos de la libertad y la igualdad mientras se esté buscando la fraternidad. No fue nada casual que 1789 es la cuna de estos dos paradigmas modernos. Como bien lo aclaró en ese año revolucionario, el cura francés EmmanuelJoseph Sieyès, el Tercer Estado es todo, es decir que el pueblo da forma tanto a la idea de nación como a la de sociedad. Igual que cada persona se transforma o debe ser transformada en ciudadano compartiendo la soberanía nacional, también cada ciudadano tiene todo el derecho de gozar la riqueza nacional mientras participa en su creación.

En el segundo apartado daré un resumen básico de la historia de la realización del ideario kibutziano, desde su primer paso en 1910 hasta enero de 2016, el momento cuando el kibutz Ein Hashofet, fundado en 1937, del que soy miembro desde 2006, empezó a implementar un sistema menos socialista que sin embargo en mi opinión es mucho más socialista que cualquier otro experimento mundial de esta índole. Claro que la intención no es cubrir en una forma exhaustiva una historia completa 
de más de un siglo, sino señalar cuales son desde mi perspectiva los hitos principales que nos pueden servir para apreciar y criticar el tema.

En la tercera y última parte, ofreceré un análisis del experimento kibutziano desde el punto de vista de los desafíos de la modernidad y más específicamente desde el desafío de la modernidad urbana. Tal vez para quienes saben algo del kibutz pueda parecerle raro analizar el mismo desde la perspectiva urbana, ya que el kibutz era y sigue siendo un emprendimiento y una realidad rural. Espero resolver esa supuesta rareza o contradicción al fin de este ensayo, por ende el lector debe tener paciencia.

No obstante, como Marx y Engels ya han valorado en su manifestó de 1848 la tendencia a ir borrando gradualmente las diferencias entre el campo y la ciudad, en muchos de sus aspectos el kibutz no es menos urbano que cualquier otra ciudad: los servicios, las comunicaciones, la infraestructura, las viviendas, el nivel de vida, la educación, la salud y así sucesivamente asumen características urbanas. Tiene sin embargo -o mejor dicho puede tener si sus integrantes así lo quieren- una ventaja derivada de su manifestación de comunitarismo. Por las dudas habría que asegurar: no un colectivismo que choca con el individualismo, sino un comunitarismo que lo enriquece.

El argumento fundamental de este ensayo es que si puede suponerse que en el futuro cercano y menos cercano, la mayoría de la humanidad-que está sostenida por economías industrializadas- va a seguir viviendo en ambientes urbanos (sean metrópolis o aldeas y pueblos), un camino adecuado para enfrentar las problemáticas sociales -la alienación, la falta de solidaridad, las brechas sociales etc.- es la formación de comunidades de cooperación social y creatividad cultural que por un lado no descartan el individualismo social y económico, pero por el otro lado lo transforma en lo que se puede definir como individualismo solidario.

Este ensayo tiene como propósito fomentar dicha idea comprobando que justamente eso fue -de una manera reducida y sin embargo vigente sigue siendo- el kibutz: un marco socio-económico y socio-cultural que tiene como política declarada y de muchas formas aplicada, fomentar el bien estar del individuo. En pocas palabras, el legado del kibutz es el intento-muchas veces realizado- de la formación de una modernidad virtuosa donde el individuo es la base de la solidaridad y no su enemigo.

\section{EL IDEARIO KIBUTZIANO}

En uno de sus más famosos refranes, Karl Marx describió como a su criterio debe funcionar una sociedad justa, recogiendo un aforismo de raíz santsimoniana: De cada cual, según sus capacidades; a cada cual según sus necesidades. Claro, ni él ni nadie que levantara la bandera del marxismo, no sabía ni puede saber exactamente cuantificar tanto las capacidades como las necesidades. Tampoco el kibutz pudo llegar a una cifra exacta, pero sí logró modelar un sistema que mientras trataba de llegar a una u otra conclusión al respecto, no olvidara que en la base de todos los sistemas e ideologías progresistas, está el ser humano.

25 años después de la caída del muro de Berlin y con la actual existencia de estados de terror como Norcorea, puede dudarse acerca de si una ideología progresista en desarrollo puede llegar a las más terribles atrocidades en la práctica. Si bien el kibutz nunca fue un estado, ni abarco más de 130000 miembros en su momen- 
to histórico más alto - circa 1980-, sin embargo se lo considera un experimento humano de escala importante. ¿Cuáles fueron entonces los secretos de su relativo éxito? La respuesta tiene dos componentes principales: el socialismo y el nacionalismo.

Desde su principio no era ningún secreto el hecho que casi cada socialista tenía su forma de entender, explicar y a veces como aplicar el mismo. En el

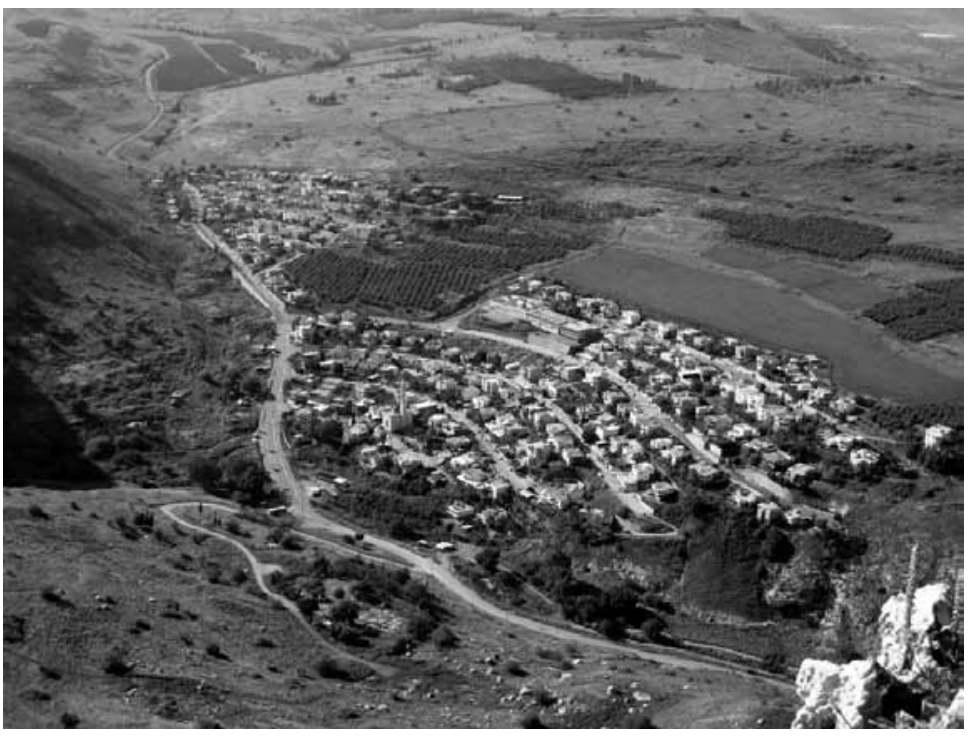

Kibbutz Degania caso de los pioneros kibutzianos, la cualidad más apreciada era constructivismo. Tomando como ejemplo el caso del primer kibutz -Degania, pegado al sur del mar dulce de Galilea (Kineret en hebreo por su forma de violín)este proyecto prácticamente empezó cuando un grupo de jóvenes judíos, todos de origen europeo oriental, sostenían que podían trabajar la tierra y cultivar trigo sin ningún jefe y en base a un préstamo de las instituciones públicas del movimiento sionista. Lo propusieron y-gozando del apoyo de un gran dirigente progresista de entonces, Arturo Rupin- lo ejecutaron. Fue entre octubre de 1909 y setiembre del 1910. Por suerte (que no siempre acompaña al campesino socialista u otro), tuvieron éxito. De este momento histórico en adelante ya fue posible el desarrollo económicos de base socialista o solidarista, con apoyo estatal pero no necesariamente bajo liderazgos de dueños de capital.

Este principio básico explica el origen y la difusión del sistema kibutziano. Es un socialismo constructivista ya que para los pioneros de esa época estaba claro que para poder repartir una riqueza hay que formarla previamente. Pero engendrar riqueza no necesariamente implica el cese de la libertad a manos de un jefe o dueño. La responsabilidad es mutual, y sucesivamente lo será el reparto de la riqueza adquirida. Y ya que es un complejo social entero -solteros, parejas, niños, enfermos, educados, menos educados, etc. y con el tiempo también jubilados y ancianos- lo cual necesita una amplia gama de servicios, la famosa división de trabajo que es necesario descubrir para conocer el kibutz como cualquier otra organización social moderna mundial. Y cuando por un lado no hay jefes; por el otro hay que producir y servir y además que no todos son iguales simplemente por ser humanos; el resultado debe ser el de aquel lema marxista: De cada cual, según sus capacidades; a 
cada cual según sus necesidades. Pero sin culto de personalidades; sin armas nucleares; sin prensa de propaganda; $\sin \mathrm{KGB}$; sin gulags. Solo o principalmente con cierta buena voluntad colectiva de quiénes aceptan ese modelo cooperativo.

Dicha buena voluntad tenía en 1910 la base ideológica no solo de la promesa socialista por entonces reconocida y apreciada en todo el mundo, sino además por el programa sionista en particular. Al menos para los pioneros de 1910 no era el antisemitismo lo que fomentó el sionismo. Era la idea del renacimiento ligado tanto al iluminismo como a la famosa primavera de las naciones que no por casualidad nació en 1848 junto con el Manifiesto Comunista. Igual que los griegos en 1821 o los franceses en 1789 , los argentinos en 1810 o los italianos en 1852, también muchos judíos empezaban a sonar con un renacimiento nacional propio, que no choca con los sueños del universalismo humano una de cuyas opciones era el socialismo con todos sus variantes más científicas o más utópicas.

El nacionalismo judío tenía algunos proyectos y uno de estos -en perspectiva quizá el único exitoso- era el sionismo. En 1897 Teodoro Herzl lideró el primer congreso donde los sionistas aclaraban su meta: El sionismo tiene por objeto establecer para el pueblo judío un hogar seguro pública y jurídicamente en Eretz Israel. Como cualquier otro órgano democrático y popular, el sionismo también tuvo ramificaciones y variantes aunque todos -es decir sionistas religiosos, sionistas liberales, sionistas apartidarios, etc- basaban su propia propuesta en lo que ellos consideraban como la interpretación más correcta de aquella meta hetzliana.

Para el sionismo socialista la conclusión era que para asegurar que la tierra de Israel se transformara de verdad en un hogar nacional, esa tierra debía ser desarrollada a base de un proyecto nacional, es decir en una perspectiva constructivista. Una construcción de esa escala aseguraría también relaciones positivas con los árabes, suponiendo que ellos van a participar del desarrollo económico en la tierra compartida. Consiguiendo este objetivo, también el aspecto político-internacional sería beneficiado, ya que tanto los árabes como el resto del mundo apreciarían el progresismo del sionismo. En caso que los árabes como parte de la comunidad internacional rechazaran el sionismo (eso es lo que lamentablemente pasó), ese ideario progresista debería seguir sirviendo como común denominador y bobina energética para la construcción de un país a base de un socialismo humano y demócrata aunque ello derivó luego en otras complicaciones como la influencia del capitalismo americano o los estados de guerra.

\section{UNA BREVE HISTORIA DE LA REALIZACIÓN DEL IDEARIO KIBUTZIANO}

En 1910 se fundó Degania, el primer kibutz. Sus miembros aspiraban a mantener íntimas relaciones sociales entre sí, concluyendo que el marco social o sea el grupo de relación interpersonal directa no debía superar las 20 o 30 personas. Pocos años más tarde, después de la Primera Guerra Mundial, otro grupo de pioneros fundó Ein Jarod, bajo otra idea de organización, proponiendo una estructura social mucho más amplia de centenares de miembros, donde las relaciones interpersonales no eran la meta principal sino más bien la búsqueda de potencia económica y como consecuencia, poder político. Estos dos caminos llevaban por supuesto dos 
estrategias económicas alternativas: mientras los que seguían el camino de Degania se bastaban con la agricultura, los de Ein Jarod apuntaban también a la industria.Entre estos dos extremos se desarrolló el movimiento kibutziano (MK).

El año 1941 fue el momento histórico más alto del MK en cuanto al volumen de población judía en Palestina: un 7\% de esa población integraba kibutz. En todo el país había poco menos de 100 kibutz, con una población total de unas 30000 personas. Ese momento histórico -la Segunda Guerra Mundial- fue momento clave para el desarrollo del kibutz ya que los británicos por necesidades militares, aumentaron la demanda de productos básicos y manufacturados, impulsando así la industrialización en todo el país, y específicamente en aquellos kibutz preparados para ello. Paralelamente, dentro del mismo contexto, los kibutz servían también como el ámbito formativo del futuro ejército judío (Palmaj), fortaleciendo por ende el espacio político del MK en el sionismo.

Cuando se establece el Estado Judío en 1948, en su dirigencia la presencia de miembros de dicho movimiento supera más que notablemente su peso poblacional relativo. Mientras que poco a poco y con la masiva migración judía al nuevo Estado de Israel ese peso relativo disminuyo de $7 \%$ a $5 \%$ y ya en 1960 a menos de $3 \%$, una quinta parte de los cuadros político-técnicos de todos los gobiernos eran miembros de algún kibutz. Fue una relación recíproca ya que el MK sirvió a su estado en su etapa constitutiva y éste le dio el respaldo económico. Pero esta época de cierta concientización política e ideológica no solo en Israel sino en todo el mundo tuvo también sus repercusiones negativas.
En 1951 como continuación de debates ideológicos de los años anteriores pero ahora dentro del contexto de una una Guerra Fría cada vez más caliente, el MK sufre una brecha social y organizativa. Decenas de kibutz adhieren a ideologías de derecha -es decir los que se identifican con el oeste sobe todo americano-y otros a ideologías de izquierda -que siguen viendo a Stalin como el sol de los pueblos-. Si bien los gobiernos israelíes de esta época están en las manos del movimiento sionista laboral o en la izquierda sionista dicha izquierda va a segregarse como en otros partes del mundo, entre cierta derecha-es decir los que van por un camino más moderado en cuanto a política económica- e izquierda -que exige más igualdad de derechos y menos mercado libre-.

Encabezados por el dinámico, a veces cruel, y siempre muy carismático Ben Gurion, los de la izquierda moderada dominan la arena política nacional. En el mismo tiempo, los líderes hegemónicos del MK tienden más a la izquierda, a veces en contradicción con las ideas de los miembros de sus kibutz. Es en este momento histórico donde el MK empieza perder peso político, proceso que llegará a su máximo agravamiento hacia fines de los años 80’. Cabe aclarar que en contradicción con otra especie de lugar común, las disidencias entre el liderazgo del MK y Ben Gurion iban más allá del cuestionamiento que se hacía de la ideología estatalista -para algunos casi fascista- de Gurion. Si bien Ben Gurion se llevaba el mundo por delante por varios motivos -su comportamiento autoritario por ejemplo- la explicación tiene más que ver con el contexto de su actuación.

Solo en el año 1949 inmigraban al Nuevo Estado 239000 judíos. En dos años más la población original de 650000 judíos se duplica- 
rá. Era un hecho insólito y en ningún otro lugar mundial ocurrió un incremento semejante. El gobierno Israelí tuvo que albergar, alimentar, educar, curar e incluir socio-culturalmente esas multitudes. Logró hacerlo mientras prevalecía una situación frágil en las fronteras, cuyos líderes árabes exigían para una segunda y última ronda negociadora, reclamando la cesión de territorios y la absorción de los refugiados palestinos -que a menudo eran víctimas de procesos violentos que ocurrieron entre los propios árabes desde 1936 hasta 1948-.

En este contexto la discusión si el reformismo de Eduardo Bernstein era un peligro para un puro socialismo o si el recibir préstamos del gobierno de USA perjudicaba la revolución mundial que Stalin estaba por realizar, parecía fuera de lugar. Era otro momento de constructivismo, muy parecido al de aquellos días iniciales de 1910. Eran otras fases de constructivismo pero a una escala inimaginable en 1910 y hacia 19501960, poco entendible para gran parte del liderazgo del MK. Solo en 1961 volvieron claramente los clásicos líderes del MK a formar parte de los gobiernos israelíes dirigidos por la izquierda sionista, hasta el cambio electoral de 1977.

Casi 30 años desde la independencia del estado judío y más de 65 años después de su primera experiencia, el MK logró cierta estabilización socio-económica. Ya habían 240 kibutz con una población general de más de 100000 personas. La vieja brecha entre Degania y EinJarod prácticamente desapareció y en casi en todos los kibutz había industria, en algunos casos avanzada, y teniendo una sociedad compuesta de tres o cuatro generaciones, nadie pretendía manejar un sistema sin jerarquías y solo por entendimiento mutuo, basado en relaciones interpersonales estrechas.
El MK aprendió como gestionar más racionalmente y el anteriormente mencionado refrán de Marx podía adaptarse a una estructura más flexible y mientras más mejoraba la economía, más flexibilidad para desarrollos sociales alternativos y alcance de metas de mayor consumo se pudo ofrecer a los miembros. En relación a la vida cotidiana de cualquier otro ciudadano israelí, el integrante del kibutz gozó tanto de las opciones socio-culturales urbanas como de cierta tranquilidad rural o más cercanía con lo natural. Es más, muchos ciudadanos israelíes miraban al kibutz como una referencia simbólica e idealizada, apreciando en abstracto sus valores pero decididamente no aptos para trasladarse a un kibutz y mucho menos, de adoptar aquella definición marxista. El MK por su lado influyó a los gobiernos para seguir con una política económica de inclusión, de responsabilidad mutual entre el ciudadano y el estado el cuál era entendido como el productor y distribuidor de servicios sociales desde la cuna a la tumba.

En mayo de 1977 cambió todo eso. El gobierno derechista-liberal manejado por Menajem Beguin, introdujo en Israel lo que en aquel entonces fue aplicado en el resto del mundo: el neo-liberalismo tipo Chicago School y en ese contexto no sólo el MK sufrió como la mayoría de los ciudadanos israelíes el Talón de Hierro del nuevo modelo económico, sino que Beguin centró su retórica neoliberal contra este movimiento. Así como el MK fue el modelo al menos simbólico para el proyecto del construcción nacional social-demócrata entre 1949 y 1977, ahora serviría como la némesis del proyecto opuesto.

Pero no fue solo asunto de símbolos y de retórica. Cuando en 1985 -la nación ya liderada por Shimon Peres como primer ministro de un gobierno de unidad nacional fruto de elec- 
ciones indecisas- Israel adopta brutalmente el consenso de Washington y ahí llega la famosa crisis económica del MK. Casi nadie recuerda que mientras 240 kibutz sufrían una tasa de interés astronómica -que fue definida 10 años más tarde como ilegal por un juez en un caso específico- más de 40000 emprendimientos productivos entraron en bancarrota.

¿Qué pasa cuando un taller mecánico, una fábrica de 50 obreros, un negocio mayorista etc. se caen económicamente? Sus trabajadores e incluso sus dueños quedan en nada y se van a la calle. Pero, ¿qué pasa si esa fábrica, ese taller o ese negocio pertenecen a un kibutz? En las mayoría de los casos eran kibutzin tanto el dueño como el trabajador y no hay ninguna calle o afuera-económico para los quebrados, dentro de un modelo socio-económico más pequeño y más cerrado. Sumando a ello el cuestionamiento anti-kibutziano llevado a cabo por la derecha gobernante, el resultado es una crisis económica y moral y cierta sensación de inviabilidad de ese modelo socio-productivo alternativo. Peor todavía fue la solución a la crisis del MK, que ocupó muchas primeras páginas de los diarios entre 1989 y 1996 . En realidad la fórmula que se conocía como plan de recuperación del $M K$, fue en realidad otra manera de un Dooh Nibor (es decir Robin Hood al revés) al agudizar la supervivencia de los comunes a favor de la concentración económica, limitando las ganancias del sector productor para favorecer al sector financiero.

Como en su pasado, en este momento también el MK fue parte de la historia, influyendo su política y futuro tanto los cambios del Zeitgeist mundial como de las circunstancias locales. En 1992 vuelve el Partido Laborista a gobernar por un instante más e Izak Rabin, hasta su muerte en 1995, trata de frenar la política de ajuste llevada a cabo por la derecha con la ayuda del autodenominado gran socialista Shimon Peres. El estado vuelve a invertir tanto en la economía de producción como en los servicios sociales y el MK, como la mayoría de la población israelí vuelve a cierta mejoría.

Si bien después del asesinato de Rabin nunca volvió el Partido Laborista a manejar el Parlamento y el Estado (salvo el breve período de Ehud Barak como Primer Ministro entre 1999 y 2000) sería razonable sostener que desde 2001 en adelante, los gobiernos israelíes tratan de controlar la economía nacional, yendo mucho menos al extremismo neo-liberal friedmanista, tan presente en Israel como en todo el mundo en la década de los años ' 80 y por ello probablemente Israel superó relativamente bien la crisis mundial del 2008. En cuanto al MK en este entorno de un marco económico relativamente estable, la mayoría de los kibutz están económicamente bien. Pero socialmente en estas dos últimas décadas -es decir desde 1996 a hoy- la mayoría de los kibutz integraron a su esencia elementos neo-liberales, es decir una clase de privatización que aleja aquella frase del marxismo del origen. Salvo en unos 50 kibutz, todos en buen estado económico, el resto de casi 200 kibutz existentes, carecen de colectivos responsables de satisfacer los necesidades de cada cual. Como en muchas manifestaciones de modernidad basadas en lógicas socialistassolidaristas y de búsqueda de una felicidad colectiva regulada por regímenes distributivos, en cierta forma el kibutz también es una utopía que quedó a medio camino.

Los conceptos del mercado y su omnipotencia frente al Estado ingresaron al MK y parece que ya no hay marcha atrás. Sin embargo, para mis criterios -que claro están influidos por 
el hecho que nací en un kibutz y soy miembro de otro y entre mi primer y tercer kibutz fui parte de un grupo que fundó otro kibutz- aún el kibutz más mercado-orientado hoy en día, es mucho más socialista que cualquier otro ejemplo en el mundo actual. Llegó el momento de comprobar y fundamentar este argumento.

En primer término, en casi todos los kibutz los medios de producción siguen perteneciendo al colectivo y sus miembros son los dueños. En cuanto a la distribución de las riquezas, si bien no es como hasta 1996, sigue siendo bastante equitativa. La brecha social dentro del MK es mucho más reducida en relación a la sociedad nacional y a sus formatos urbanos. La responsabilidad mutual sigue en pie, a pesar que no como hasta 1996 ya que hoy hay más interés en el rendimiento económico y no cualquier problema social está dispuesto a solucionarse mediante el financiamiento del sistema. Otro elemento sumamente importante es la democracia participativa que sigue manejando el kibutz, en algunos casos más aceitada que en el sistema original, donde el carisma en el sentido weberiano era mucho más influyente y ahora ya no. Y como último elemento es relevante la cohesión socio-cultural ya que el kibutz sigue siendo una verdadera comunidad y existe cierto orgullo de pertenencia.

Resumiendo entonces: el kibutz hoy en día, tanto en su peor proceso de privatización, sigue siendo una entidad dominantemente socialista, aunque imperfecta por su economía, sociedad, cultura y política. Todas ellas incluyen y la inclusión fue el factor más importante del socialismo desde su aparición hace 200 años.

Sus mejores logros se produjeron en un entorno nacional y demócrata y tal fue el caso del sionismo y del Estado de Israel, dos fenómenos históricos que deben gran parte de su vigencia al éxito de kibutz como modelo de unidad social. Sin la energía producto de la propia voluntad de los primeros pioneros kibutzin ni el sionismo ni el Estado de Israel podían haber prosperado. Esos pioneros solían cantar: anu banu artza livnot $u$ le hibanot ba (vinimos a nuestra tierra para construirla y ser construidos por ella).

La paradoja o tal vez la ironía histórica, está en el hecho que ya con un estado constituído, es decir una herramienta política poderosa, para el kibutz se abrió tanto la oportunidad de su consolidación como la posibilidad de su colapso. El estado moderno, incluso el más democrático, es una encarnación del viejo mito del Golem como realización moderna de la antigua fabula de un cuerpo sin espíritu propio. Se lo puede llenar con socialismo-progresista-incluyente o con neo-liberalismo. Cuando nació el Golem israeli, los magos que tiraban las cuerdas levantaban la bandera del viejo Marx. En 1977 los operadores del mismo Golem tenían puesta la camiseta de Milton Friedman.

\section{EL KIBUTZ Y LO URBANO}

Un último punto es discutir el experimento kibutziano desde el punto de vista urbano. Es cierto que el kibutz es una realidad rural, pero viéndolo más cuidadosamente tiene mucho del modelo urbano: los servicios que ofrece el kibutz, las comunicaciones que gozan sus habitantes, la infraestructura, las viviendas, el nivel de vida, la educación, la salud y así sucesivamente. Marx y Engels deberían estar contentos con los logros del kibutz, ya que en su Manifiesto de 1848 hablaban favorablemente sobre la tendencia a ir borrando gradualmente las diferencias entre el campo y la ciudad, 
Tiene sin embargo -o lo puede tener si sus integrantes así lo quieren- una ventaja respecto del modo de vida urbano en cuanto el comunitarismo. Por las dudas hay que aclarar: no un colectivismo que choca con el individualismo, sino un comunitarismo que lo enriquece. Por ende, suponiendo que en el futuro cercano o menos cercano la mayoría de la humanidad sostenida por la economía industrializada va a seguir viviendo en ambientes urbanos (sean metrópolis o aldeas y pueblos) un camino adecuado para enfrentar las problemáticas sociales de esos ambientes -la alienación, la falta de solidaridad, las brechas y desigualdades sociales, la no-inclusión, etc.- es la formación de comunidades de cooperación social y creatividad cultural que por un lado no descartan el individualismo social y económico pero por el otro lo puede transformar en lo que se puede definir como un individualismo-solidario.
El kibutz fue y de una manera reducida pero sin embargo vigente lo sigue siendo, un marco socio-económico y socio-cultural que tiene como política declarada y de muchas formas aplicada, fomentar el bien estar del individuo. El legado del kibutz pues, era y es la formación de un modernismo sano donde el individuo es la base de la solidaridad y no su enemigo. A esta altura del desarrollo de la historia moderna, parece que eso no será fácil de conseguir sin un empuje o fundamento macro-económico. He aquí el papel fundamental de nuestro Golem ciego, faltante de conciencia propia, papel fundamental y único del discurso socio-cultural abierto, sano, justo, responsable. En una palabra: histórico. Así es: la clave al futuro de la humanidad está en su pasado. 


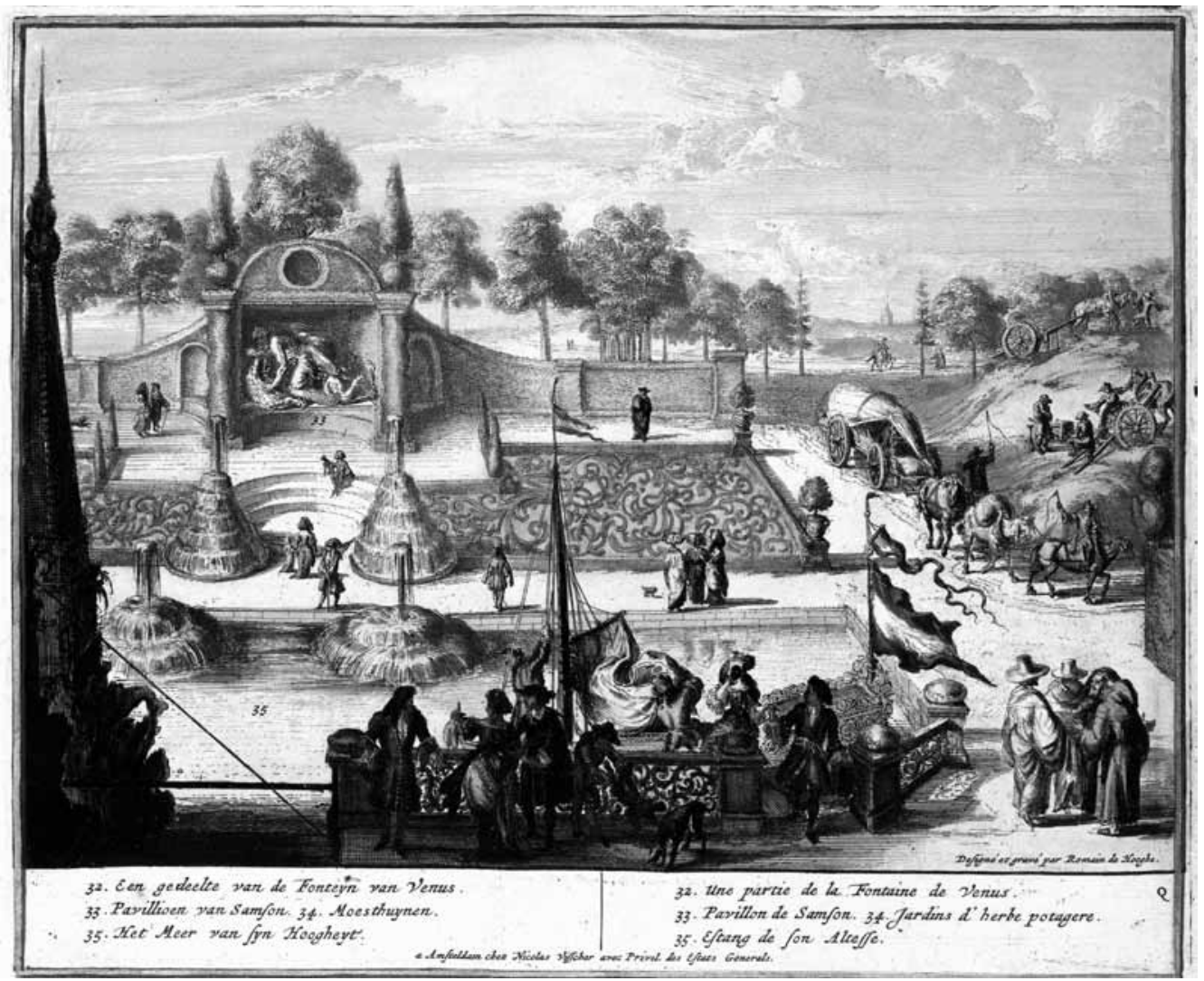

